\title{
Management of Voltage Profile and Power Loss Minimization in a Grid-Connected Microgrid System Using Fuzzy-Based STATCOM Controller
}

\author{
Mezigebu Getinet Yenealem $\left(\mathbb{D},{ }^{1}\right.$ Livingstone M. H. Ngoo, ${ }^{2}$ Dereje Shiferaw, ${ }^{3}$ \\ and Peterson Hinga ${ }^{4}$ \\ ${ }^{1}$ Department of Electrical Engineering, Pan African University Institute for Basic Science, Technology and Innovation, \\ P.O. Box 62000-00200, Nairobi, Kenya \\ ${ }^{2}$ Department of Electrical Engineering, Multimedia University, P.O. Box 30305, Nairobi, Kenya \\ ${ }^{3}$ School of Electrical Engineering, Addis Ababa Institute of Technology, P.O. Box: 1176, Addis Ababa, Ethiopia \\ ${ }^{4}$ School of Electrical Engineering, Jomo Kenyatta University of Agriculture and Technology, P.O. Box 62000-00200, \\ Nairobi, Kenya \\ Correspondence should be addressed to Mezigebu Getinet Yenealem; mezigebudn@gmail.com
}

Received 1 May 2020; Revised 24 June 2020; Accepted 9 July 2020; Published 25 August 2020

Academic Editor: Andrea Bonfiglio

Copyright (c) 2020 Mezigebu Getinet Yenealem et al. This is an open access article distributed under the Creative Commons Attribution License, which permits unrestricted use, distribution, and reproduction in any medium, provided the original work is properly cited.

\begin{abstract}
The expansion of renewable energy is continuing powerfully. Electrical system ought to transmit power with diminished loss, improved power quality, and reliability while pleasing the need of customer's load demand. Nevertheless, owing to the exhaustion of fossil fuels and their environmental impact, the availability of quality, stable, and reliable power in developing countries is worrying. Integrating a solar-wind based microgrid to the distribution network is the more feasible and best alternative solution to gratify the customer intensifying power demand while seeing the strict environmental regulations of generating power. However, the microgrid system connected in a distribution network has diverse problems and challenges. The problems comprise the development of voltage sag and swell, voltage unbalance, and power losses because of the intermittent nature of PV and wind resources. The objective of this study is to integrate microgrid system with STATCOM (static synchronous compensator) controller to ensure the higher power flow with enhanced voltage profile and reduced power loss. MATLAB/PSAT is used to model microgrid and STATCOM controller connected to the grid. Proportional integral (PI) and fuzzy logic controllers (FLC) are also applied to control the STATCOM. The effectiveness of STATCOM with microgrid integration is tested by connecting to the main distribution system using standard IEEE 30-bus system. Finally, it was observed that STATCOM raises the capacity of the distribution line and contributes to voltage profile improvements and power loss reduction.
\end{abstract}

\section{Introduction}

Today's energy consumption has steadily increased, yet the investments in conventional power system and usage of fossil fuels have declined correspondingly. Thus, electrical energy systems worldwide are working under a stressed condition resulting in less reliability, poor power quality, frequent power outages, and high-energy price [1]. In addition, the conventional electrical grid system is a strictly hierarchical and a one-way pipeline. However, an increasing energy demand, rapid development of technological advancement, energy crisis, power outages, economic incentives, and societal awareness of environmental concern are leading research areas to renewable energy and distributed power network systems with high-power reliability, stability, quality, and security requirements for improvement of existing network and topology [2].

By applying several control techniques, the increased penetration of solar and wind micro sources at different locations changes the structure of the conventional power 
system into an interconnected two-way, high-efficiency, high-reliability, and a stable network system termed as microgrid [3]. So that microgrid is the ultimate solution for the current energy problem which is often fueled by the renewable energy resources.

Renewable energy sources, particularly PV and wind, have intermittent and unpredictable nature depending on weather and climatic changes. Along with this, the network system produces a high fluctuation in their outputs and integrating the microgrid system alone in distribution network is not entirely safe in meeting the demand for the load [4]. Due to the fluctuations, instability, poor voltage regulation, less reliability, and degraded efficiency the power system has experienced [5], maintaining the system voltage profile with fluctuating micro sources is a big challenge.

Implementing reactive power compensation devices is an embryonic need for steady-state operation of the system. Reactive power causes a negative impact on effectiveness and capacity of the power system and involves energy losses and high costs as well as rising of power quality problems [6]. To solve the power quality issues, fixed capacitor banks and synchronous condensers have been used for several years [7]. However, such compensation of reactive power has some drawbacks that include high losses, slow response time, rigidity, high cost, and large dimensions.

In order to tackle the power system operational challenges related to monitor, operation, and control, Flexible Alternating Current Transmission System (FACTS) devices were introduced and established in the late 1980s [8]. However, electronics topologies are required for the accurate and potential operation of the FACTS devices to increase the system security, reliability, quality, and performance [9]. The most commonly used converter in FACTS family due to its fastest response in reactive power compensation is the static synchronous compensator (STATCOM). It is a shunt connected reactive compensation device. Using STATCOM, power quality problems such as voltage fluctuation, voltage unbalance, voltage sag, poor power factor, and unbalanced load are compensated [10].

By increasing the transmission lines capacity, STATCOM eliminates the need to build new lines. Various control strategies are used to allow operation of the power system within the operating limits required.

The most commonly utilized controllers of STATCOM are Proportional-Integral (PI), Proportional-Integral-Derivative (PID), fuzzy logic controller (FLC), and Artificial Neural Networks- (ANN-) based controllers [11]. In the commercial STATCOM controller, PI type controllers are consolidated and adequate due to their satisfactory dynamic responses. Subsequently, the flow research is centered around acquiring an increasingly hearty and versatile activity of STATCOM for varieties of the crossover power system.

In recent years, various researches have been presented on STATCOM. Research on STATCOM for Reactive Power Flow Control in microgrid system has been presented. But it only worked for current control of the microgrid integrated distribution system and did not deal with voltage fluctuation control [12].
The penetration of microgrid system to the radial distribution network to minimize the power loss has been reported in [13]. But the integrated wind and PV micro sources were not concerned about voltage profile improvement and mitigating disturbances using FACTS controllers.

Voltage control by means of reactive power support for a hybrid power system network has been proposed in [14]. But the work did not utilize STATCOM to diminish the voltage fluctuation with the bundle side converter.

Reactive power control and power factor improvement using STATCOM, SVC, and UPFC alternatively for wind energy based microgrid integration to the network have been reported in [15]. However, the work did not use FACTS controllers to reduce voltage fluctuation caused by the random nature of wind and solar energy for improving power quality and reliability.

The literature review shows that there is very little research on STATCOM controller-based voltage fluctuations and loss minimizations caused by solar-wind based grid connected microgrid systems. With the growing installation of PV and wind based microgrid system, the FACTS controllers still need enhancements by tuning of controller's gain and broad investigations have to be made under various operating conditions.

In the STATCOM controller, the controller gains were usually designed based on a linearized system equation for the system under a nominal load condition [10]. These controller gains stayed fixed in a daily activity of the STATCOM. Since the load changes with time in daily operation of the STATCOM, the network grid, the closed loop eigenvalues, and the dynamic performance will change. In this way, to keep up great unique reactions, the controller should be adjusted depending on system stacking conditions.

Artificial Neural Networks (ANNs) have been proposed to adapt to the controller gains of the STATCOM [16-18]. But they require offline training which is usually timeconsuming. In addition, they need no inference signal and evaluation function in real-time applications.

In this study, the objective is to increase the reliable operating limit of the microgrid integrated power system network by incorporating fuzzy logic based STATCOM controller for reactive power compensation. Also, it is aimed to reduce the voltage fluctuation and power loss occurring due to the varying nature of renewable energy sources.

To the best of the authors' knowledge, a study dealing with the grid connected microgrid system voltage fluctuation improvement and power loss minimization using fuzzy logic based STATCOM controllers has not been published.

This paper is organized as follows. Section 2 presents the methodology of the research, Section 3 presents the simulation results and discussions, Section 4 gives the summarized results, and Section 5 discusses the conclusion of the study.

\section{Methodology}

The objective of this study is to build a single line diagram of the IEEE 30 standard bus system model for conducting power flow analysis using MATLAB/PSAT. Furthermore, 
the paper aims to find out the improved voltage profile, reduced loss, and increased power system performance by integrating microgrid and FACTS devices to the main grid.

2.1. Wind Power System Modelling. Today, the most preferred generators for wind energy conversion systems are doubly fed induction generator (DFIG) [19]. It is the ideal generator used in wind energy systems with adjustable speed. The term "doubly fed" means the stator voltage is produced from the three-phase power supply and the buck-to-buck converter produces the rotor voltage. For either the normal or fault condition, DFIG is realized by regulating the buck-to-buck converters using different controllers [20]. The exact equivalent circuit of the system has been presented in [5].

DFIG has two progressive converters as rotor side control and grid side control as realized in [17]. In the grid side control circuit of the wind, Vbus (grid voltage), $Q$ (reactive power component), and three-phase current component ( $\mathrm{Ia}, \mathrm{Ib}$, and $\mathrm{Ic}$ ) are taken in the grid side control circuit of the wind and Vbus and Id and Iq are controlled. With space vector changes, voltage components ( $\mathrm{Vd}$ and $\mathrm{Vq}$ ) and current segments (Iq and Id) are changed to threephase signals. The angles are determined with PLL (phaselocked loop) by utilizing voltage esteems and utilized in space vector transformation.

The aerodynamic model of the power of the rotor as a function of air flow on the blades has been shown in [18] and the mechanical power extracted $(\mathrm{Pm})$ from a wind turbine is given in the following equation [21]:

$$
P_{m}=\frac{1}{2} \rho A v_{1}^{3} C_{P}(\lambda, \beta),
$$

where $\quad C_{P}(\lambda, \beta)=0.5176\left(116 / \lambda_{i}-0.4 \beta-5\right) e^{-21 / \lambda i}+$ $0.0068 \lambda 1 / \lambda_{i}=1 /(\lambda+0.08 \beta)-0.035 /\left(\beta^{3}+1\right)$.

$C p$ is a power coefficient, which varies with tip speed ratio of wind turbine $(\lambda)$, pitch angle $(\beta)$, and air density $\left(\rho=1.225 \mathrm{~kg} / \mathrm{m}^{3}\right)$.

2.2. Photovoltaic System Modelling. Photovoltaic (PV) cells can convert photons of light into electrical energy. PV cells are connected in parallel to increase the current and in series to increase voltage. A photovoltaic cell for its forward-biased characteristics using a one-diode model is detailed in $[22,23]$. The equivalent circuit of a one-diode PV cell consisting of photo lights $\left(I_{p h}\right)$, series $\left(R_{s}\right)$, and shunt $\left(R_{s h}\right)$ resistors is modelled in $[23,24]$ and the current flow of PV system can be determined in the following equation:

$$
I_{p v}=I_{p h}-I_{o}\left(e^{q\left(V_{p v}+I_{p v} R_{s}\right) / \gamma K T}-1\right)-\frac{\left(V_{p v}+I_{p v} R_{s}\right)}{R_{s h}},
$$

where $k$ is Boltzmann constant $\left(1.38 \times 10^{-23} \mathrm{~J} / \mathrm{K}\right), T$ is the absolute temperature $(\mathrm{K}), q$ is electron charge $\left(1.6 \times 10^{-19} \mathrm{C}\right)$, $r$ is linearity factor, $V_{p v}$ is the output voltage of the solar cell, and Io shows the dark saturation current value. The mathematical model of the photovoltaic system with perturb and observe $(\mathrm{P} \& \mathrm{O})$ algorithm used for the maximum power point tracking (MPPT) is presented in [25].

2.3. Power Flow Analysis. The current and voltage measurements of the network in each bus and active and reactive power flow in each line are analyzed using power flow analysis method. Newton-Raphson (N.R), Gauss-Seidel (G.S), and fast-decoupled (FD) power flow methods are the most widely used strategies of power flow analysis. N.R is the most preferred because of its quadratic convergence, more computation time per iteration, and being efficient for large networks $[26,27]$.

2.3.1. Power Flow in STATCOM Controller. Static synchronous compensator (STATCOM) is a parallel-connected $\mathrm{DC}$ to $\mathrm{AC}$ converter. If it is overexcited, it acts as a capacitor which provides reactive power and acts as an inductor when underexcited and absorbs reactive power. Figure 1 shows the modified equivalent circuit of STATCOM connected to bus A [22].

Based on Figure 1, the active and reactive power equations when STATCOM is connected are calculated as follows [28]:

$$
P_{s h}=v_{s h}^{2} G_{s h}+v_{s h} v_{A}\left[G_{s h} \cos \left(\delta_{s h}-\theta_{A}\right)+B_{s h} \sin \left(\delta_{s h}-\theta_{A}\right)\right] \text {, }
$$

$Q_{s h}=-v_{s h}^{2} B_{s h}+v_{s h} v_{A}\left[G_{s h} \sin \left(\delta_{s h}-\theta_{A}\right)-B_{s h} \cos \left(\delta_{s h}-\theta_{A}\right)\right]$.

2.4. Control ofStrategy ofSTATCOM. The role of the control system is to increase or decrease the DC voltage of the capacitor, so that the produced AC voltage has the appropriate amplitude for the reactive power needed. The control system must also keep the voltage produced by the AC in phase with the system voltage in the STATCOM link bus to either produce or absorb reactive power. PLL (phase-locked loop) synchronizes the system voltage and provides a reference angle to the measuring device. The STATCOM voltage and current positive-sequence elements are measured, using phase-to-dq transformation and a running-window average. The voltage regulator block (outer loop) measures the reactive current reference Iqref used by the current regulator block (inner loop) from the calculated voltage (Vmeas) and the reference voltage (Vref). The current regulator output is the $\alpha$ angle which is the inverter voltage's phase change in relation to device voltage. Firing Pulses Generator generates pulses from the PLL output (w.t) and current regulator output ( $\alpha$ angle) for the inverters of STATCOM. The block diagram of the proposed STATCOM control strategy is shown in Figure 2.

\subsubsection{Fuzzy-PI Controller Design for STATCOM Controller.} Linear PI controllers are entrenched in traditional control system and it is regularly used as a benchmark against 


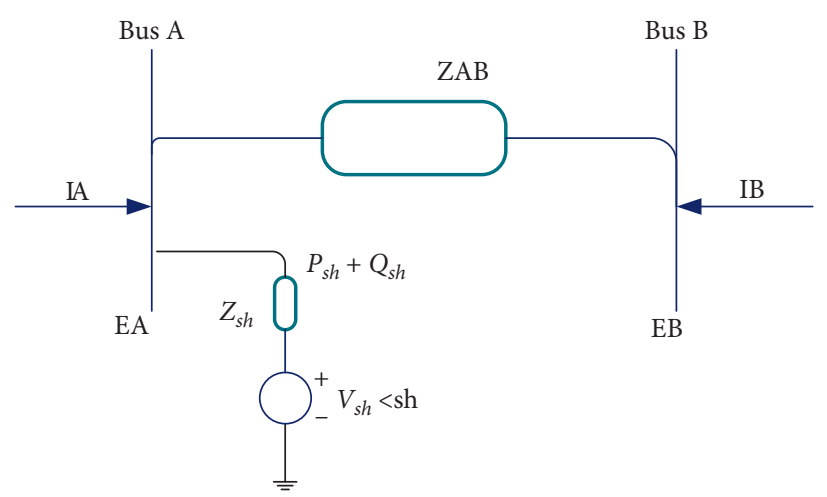

Figure 1: Modified equivalent circuit of STATCOM.

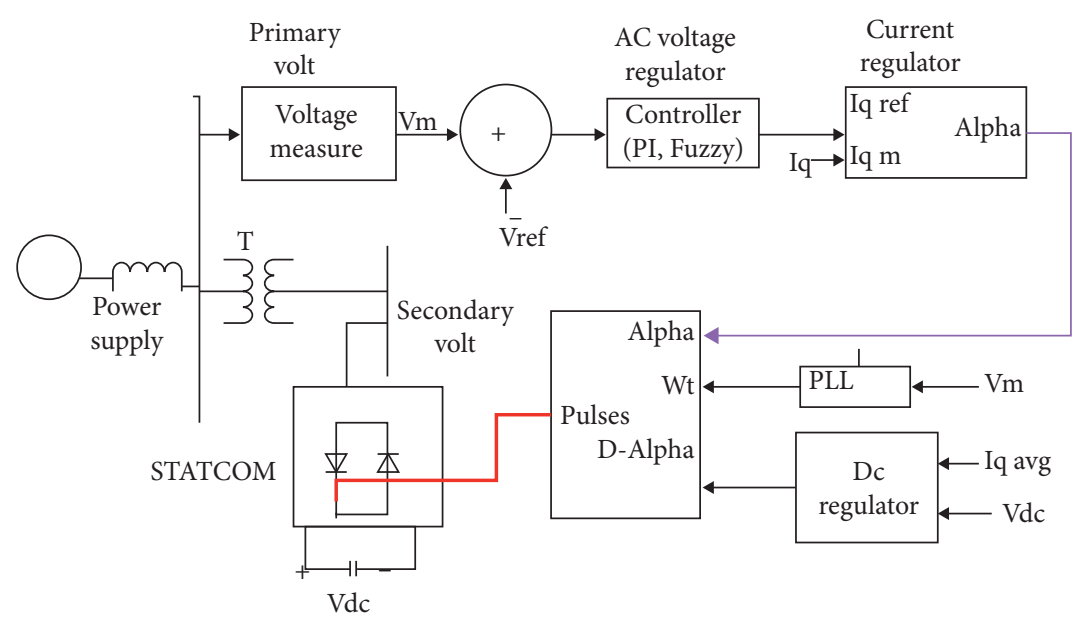

FIgURE 2: Proposed control scheme diagram of STATCOM.

different kinds of controllers [29]. Since PI controller is linear with fixed parameter, it is not usually suitable and robust for strongly nonlinear systems.

Hence, challenges urged the creation of an effective technique to solve such problems. One of these methods is adaptive tuning of the PI controller which is used to adjust the gain of integral controller at any disturbance that leads to an adjustment in device condition using fuzzy logic control. Fuzzy logic controller (FLC) is a versatile controller and suits complex environments. Like Boolean or crisp logic, fuzzy logic tackles vagueness and ambiguity. Fuzzy logic is a rulebased operation, which is simple to design for any number of inputs and outputs [30].

FLC's structure consists of mainly five parts, namely, knowledge base, fuzzification, inference, rule base, and defuzzification, as shown in Figure 3.

In fuzzification, crisp values of input are converted into linguistic values, in compatibility with the fuzzy set. The high quality of fuzzification approach is dependent on the interference signal [31].

Rule base is basically the control methodology of the system. It is for the most part acquired from master information or heuristic as a lot of If-Then principles.

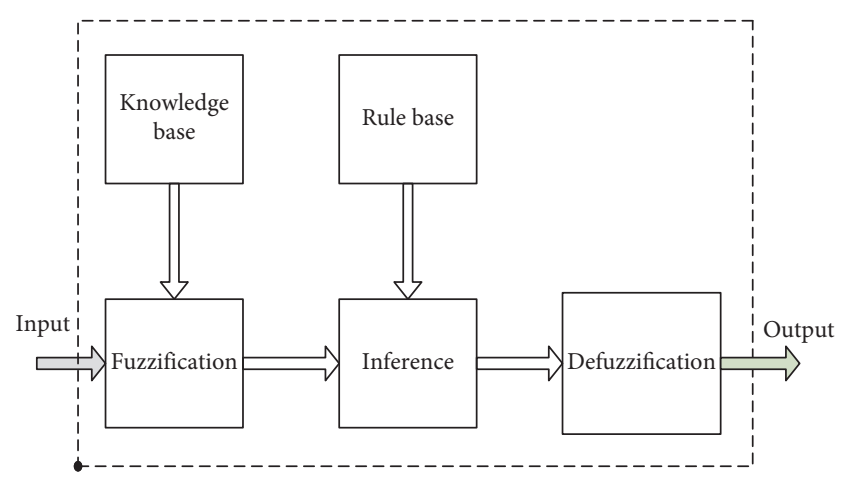

Figure 3: Basic structure of fuzzy logic control system.

The knowledge base comprises a database of the plant and attendant control goal. It provides all the essential descriptions for the fuzzification process.

The inference mechanism is also called fuzzy model which applies fuzzy reason to rule base to get a proper output. The most commonly used fuzzy inference mechanisms are Takagi-Sugeno and Mamdani fuzzy systems. Mamdani is suitable for slow-changing dynamic systems, 


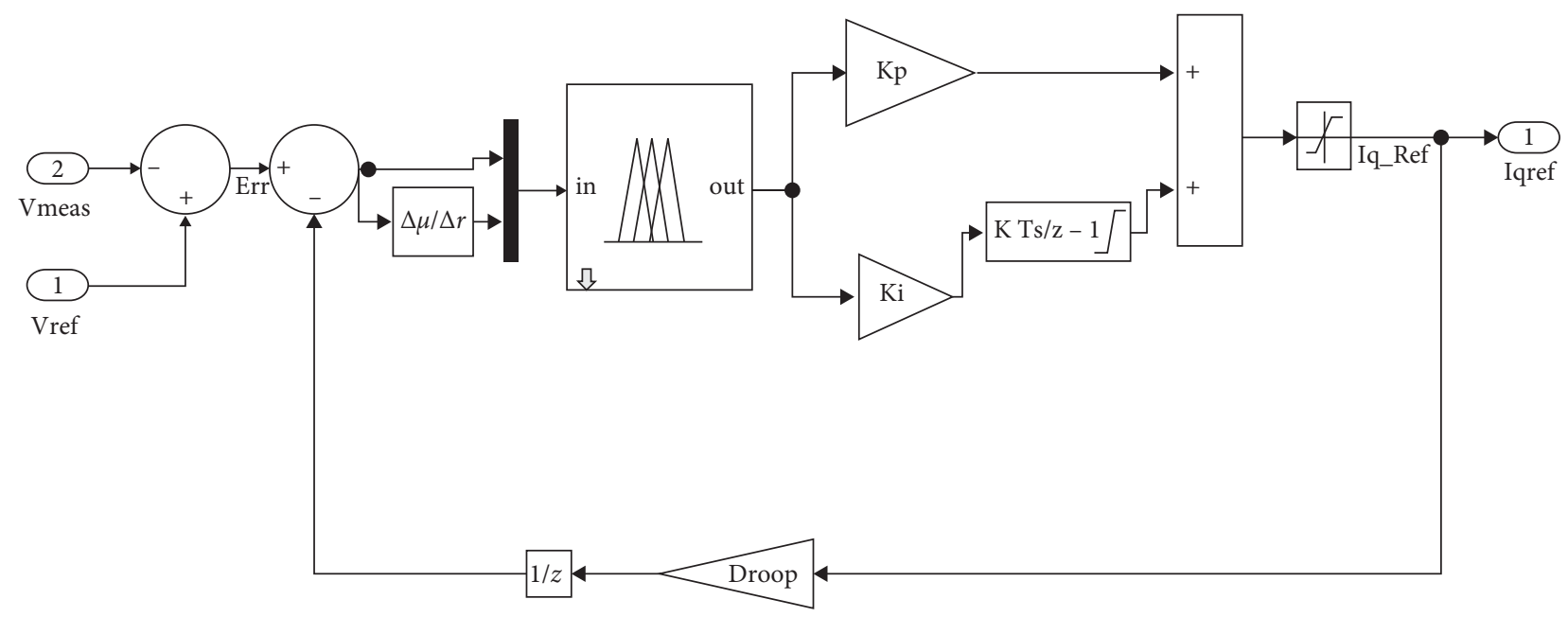

FIgURE 4: Structure of fuzzy-PI controller.

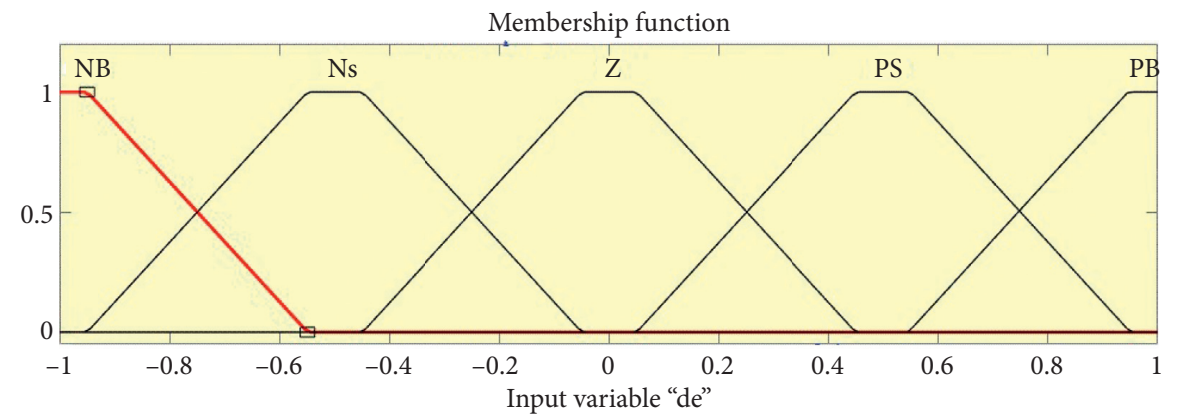

(a)

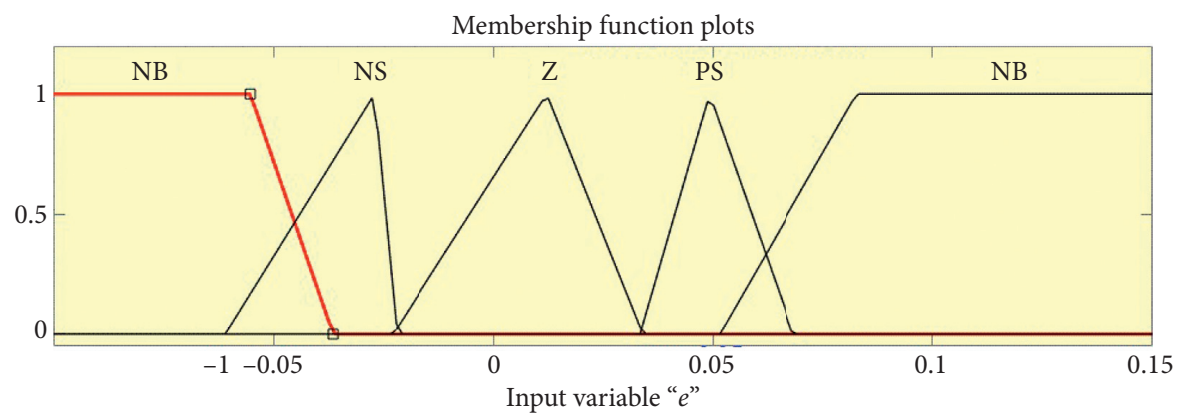

(b)

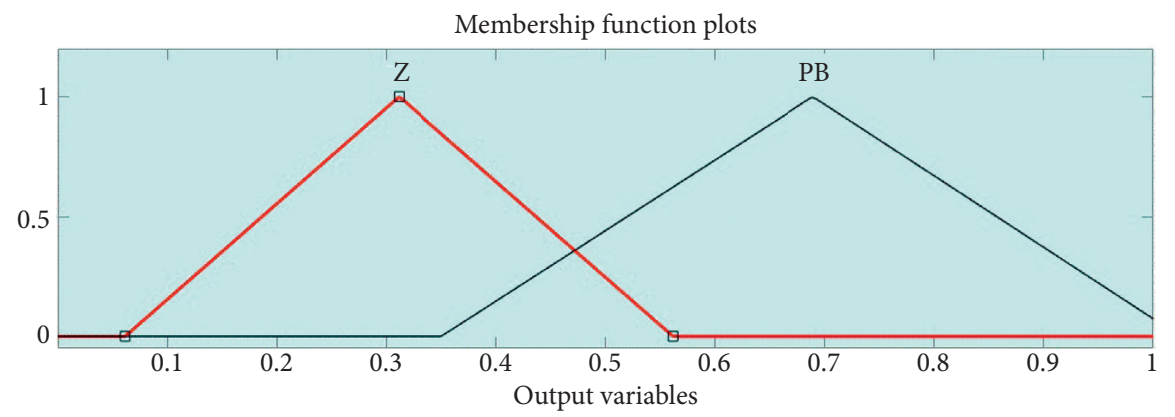

(c)

Figure 5: Triangular membership functions: (a) and (b) for input variables and (c) for output variable. 
TABle 1: Rule base for fuzzy-PI controller.

\begin{tabular}{lccccc}
\hline $\mathrm{d} e / e$ & $\mathrm{NB}$ & $\mathrm{NS}$ & $\mathrm{Z}$ & $\mathrm{PS}$ & $\mathrm{PB}$ \\
\hline $\mathrm{NB}$ & $\mathrm{PB}$ & $\mathrm{PB}$ & $\mathrm{PB}$ & $\mathrm{PB}$ & $\mathrm{PB}$ \\
$\mathrm{NS}$ & $\mathrm{PB}$ & $\mathrm{PB}$ & $\mathrm{PB}$ & $\mathrm{PB}$ & $\mathrm{PB}$ \\
$\mathrm{Z}$ & $\mathrm{Z}$ & $\mathrm{Z}$ & $\mathrm{Z}$ & $\mathrm{Z}$ & $\mathrm{Z}$ \\
$\mathrm{PS}$ & $\mathrm{PB}$ & $\mathrm{PB}$ & $\mathrm{PB}$ & $\mathrm{PB}$ & $\mathrm{PB}$ \\
$\mathrm{PB}$ & $\mathrm{PB}$ & $\mathrm{PB}$ & $\mathrm{PB}$ & $\mathrm{PB}$ & $\mathrm{PB}$ \\
\hline
\end{tabular}

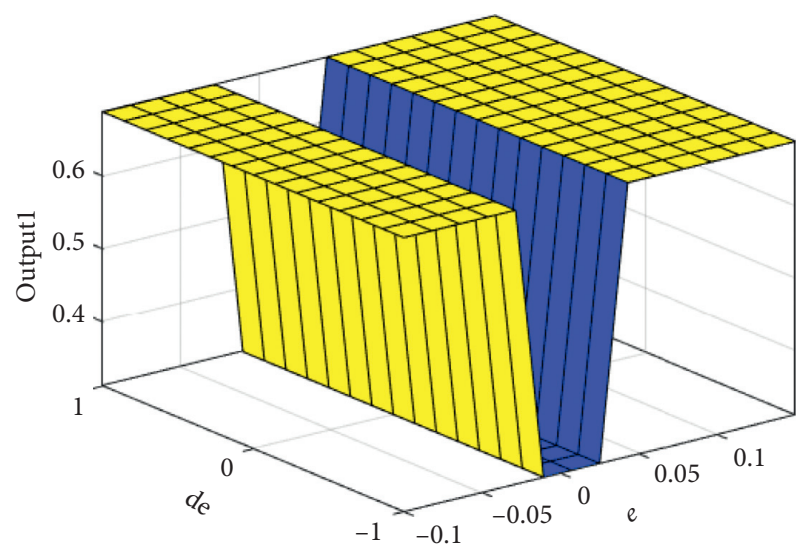

FIgURE 6: Surface viewer for rule base.

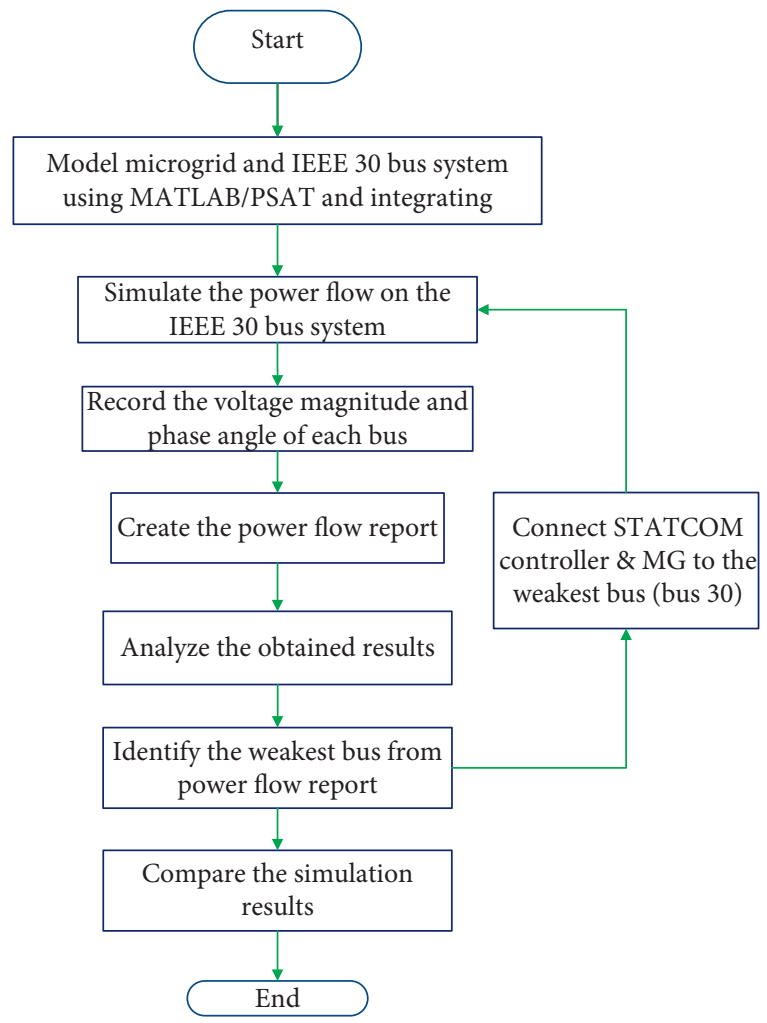

FIgURE 7: Flow diagram of simulation using MATLAB/PSAT.

while Takagi-Sugeno is suitable for fast-changing dynamic systems. In this work, due to its intuitive, widespread acceptance and being well suited to human input, Mamdani fuzzy inference system is used.
The defuzzification converts the range of output variables into corresponding universe system and yields a non-fuzzycontrol action from an inferred fuzzy process which can be transformed into crisp values.

The structure of the fuzzy-PI controller used for STATCOM controller simulation is shown Figure 4. It has two inputs and one output. Inputs of the controller are error (e) of measured and reference voltage and change of error (de).

(1) PI Controller Structure. The PI controller used in this study has the following mathematical expression:

$$
u=k_{p} e+k_{i} \int e \mathrm{~d} t
$$

where $u$ is the control output, $k_{i}$ and $k_{p}$ are the integral and proportional gains, and $e$ is the error input to the controller.

(2) Fuzzy Logic Control Structure. As shown in Figure 4, the fuzzy logic controller controls the peak voltage in the reactive control loop of STATCOM. The error $(e)$ and change of error (de) are calculated and regulated, respectively. The regulated values of " $e$ " and "de" are given to the fuzzy logic controller as an input.

The control output of fuzzy is multiplied with a PI controller output gain factor $(\mathrm{Kp})$ to get proportional derivative and with another gain (Ki) of PI controller again multiplied and integrated to get proportional-integral. Then, both values are multiplied to get a combined proportional-integral-derivative action from fuzzy logic controller (FLC).

In this study, we preferred triangular membership function for both input and output fuzzy sets. The membership function of error $(e)$ and change of error $(\mathrm{d} e)$ chose five fuzzy sets defined as Positive Big (PB), Positive Small (PS), Zero (Z), Negative Small (NS), and Negative Big (NB) and two fuzzy sets for output named as Positive Big (PB) and Zero $(Z)$ were used as shown in Figures 5(a)-5(c), respectively.

The fuzzy-PI controller rule base and surface viewers are illustrated in Table 1 and Figure 6.

The simulation study is done for changing of Iqref from $0 \mathrm{~A}$ to $+200 \mathrm{~A}$ at $0.5 \mathrm{sec}$., from $+200 \mathrm{~A}$ to -200 at $0.8 \mathrm{sec}$., and from $-200 \mathrm{~A}$ to $0 \mathrm{~A}$ at $1.1 \mathrm{sec}$. Performance of fuzzy-PI controlled STATCOM is evaluated for changes in Iqref. The following are considered as preconditions for normal operation of the proposed system.

(a) At the moment of disturbance, when the voltage magnitude at bus is far towards positive from reference value, the error value is also increased. If the error value is more than +0.025 , the change of integral gain must be large for damped in voltage magnitude.

(b) At the moment of disturbance, when the voltage magnitude at bus is far towards negative from reference value, the error value is also increased. If the error value is less than -0.025 , the change of integral gain must be large for damped voltage magnitude. 


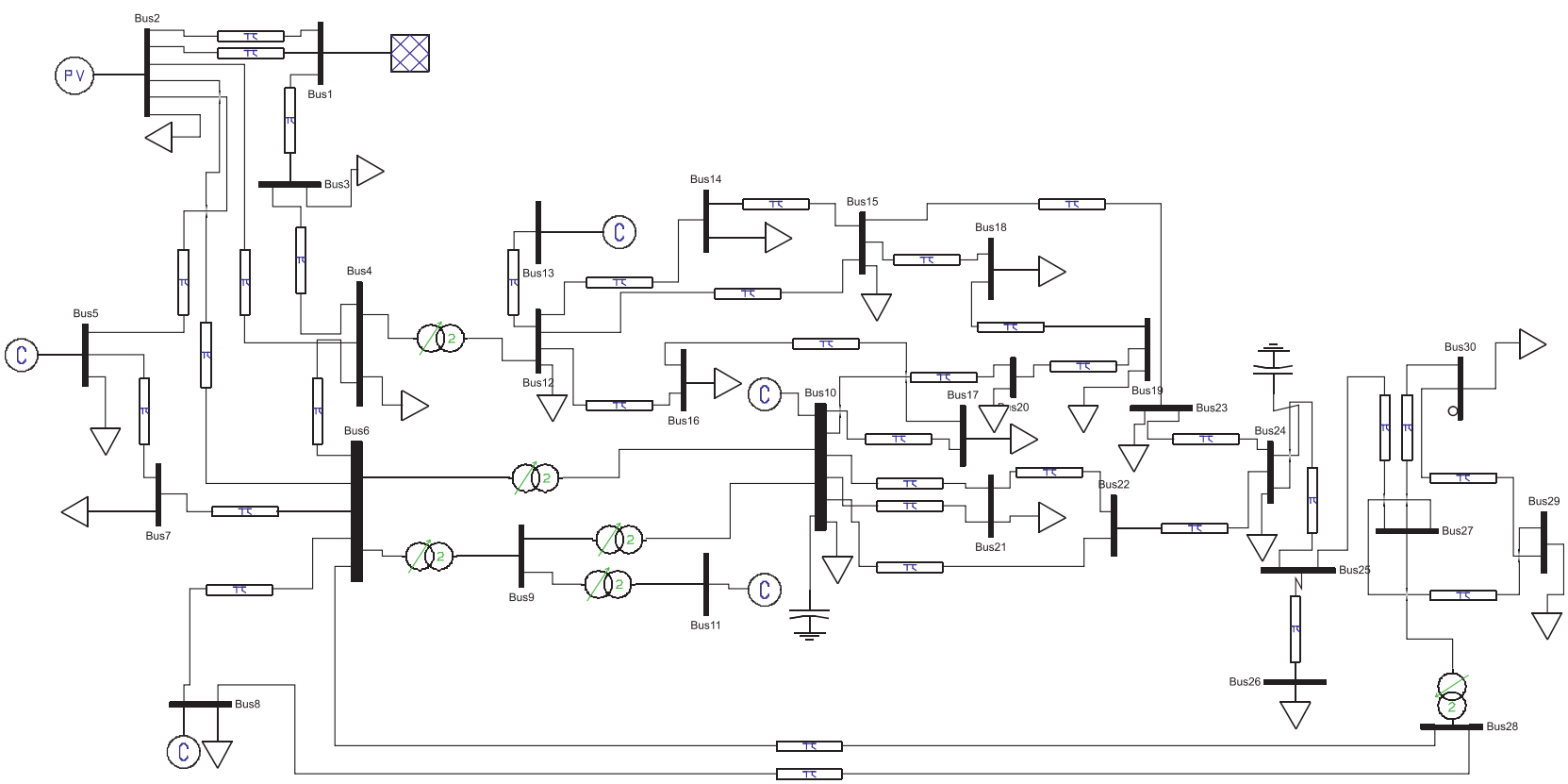

Figure 8: IEEE 30-bus system model using PSAT.

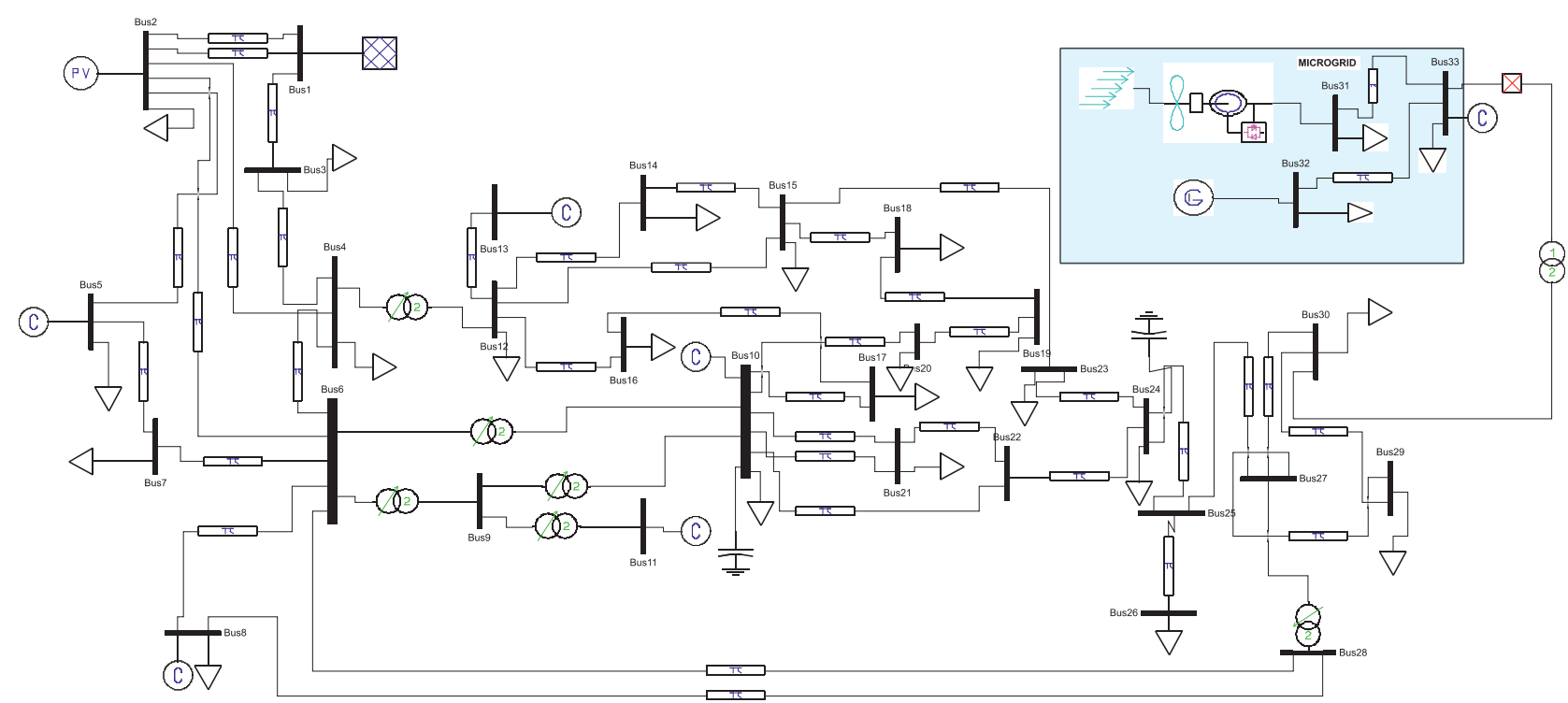

Figure 9: Integration of microgrid system in IEEE 30-bus test.

(c) The error value is limited within $+0.025>e>-0.025$ when disturbance is vanished. Moreover, the change of integral gain must be zero and the output of fuzzy-PI controller is the fixed value of integral gain.

2.4.2. Selecting the IEEE 30-Bus System. This work considers the IEEE 30-bus system. The bus, line, and transformer data of the IEEE 30-bus standard system are taken from [32]. The network consists of 7 generators, 37 lines, and 6 transformers, while loads are interconnected to 21 buses. The rated base value $100 \mathrm{MVA}$ is taken for power and base voltages of $69 \mathrm{kV}, 13.8 \mathrm{kV}$, and $18 \mathrm{kV}$ are used in three different regions. Bus 1 is considered as a slack bus. All units are in per-unit values as per bus and line parameters are in p.u.

2.4.3. Software Used. The open-source MATLAB interfaced freely downloadable system called PSAT 2.1.10 (Power system Stability Analysis Toolbox) software is used to model the systems. It is a graphical user interface (GUI) and Simulink editor toolbox used for power system model, control, analysis, and operation. PSAT can conduct simulations of continuation power flow (CPF), small-signal stability analysis (SSSA), power flow (PF), and time-domain simulation (TDS). 


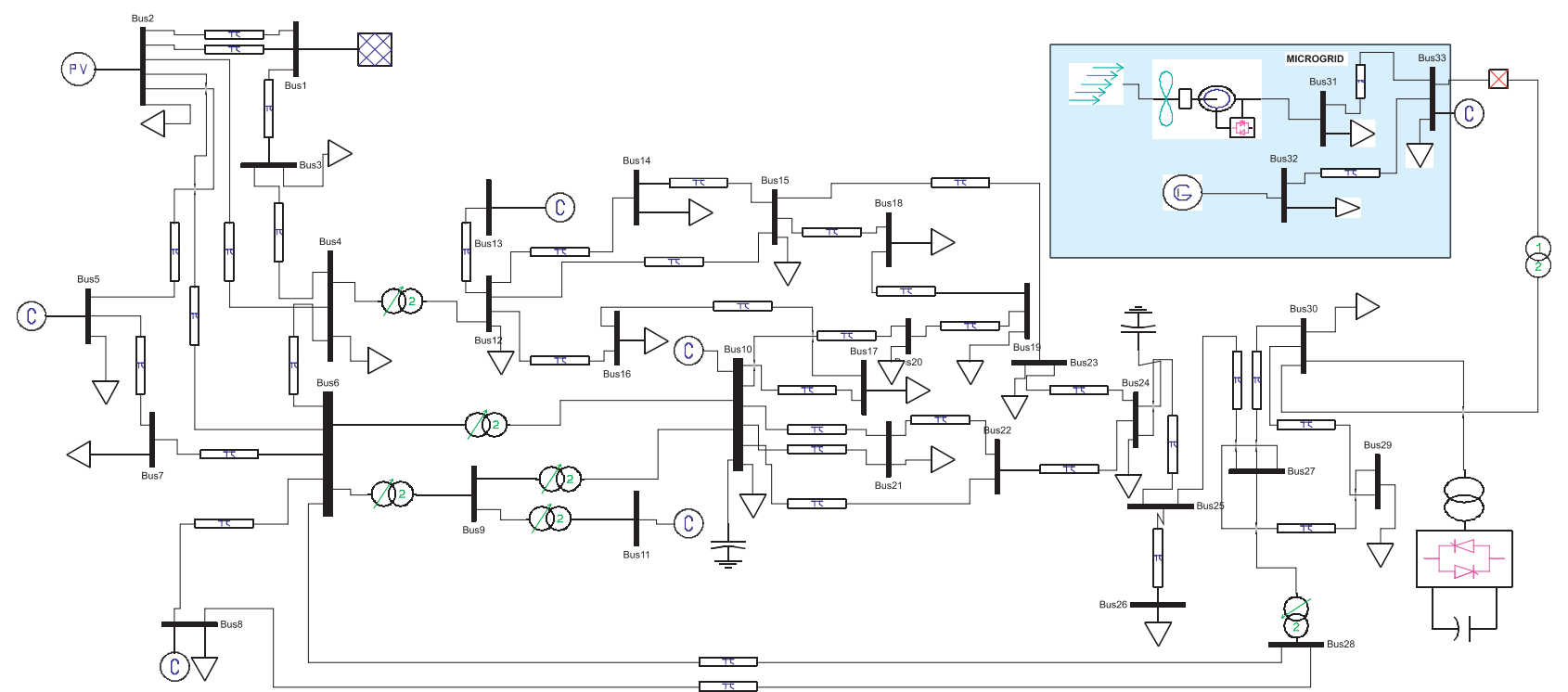

Figure 10: Base case with microgrid and STATCOM controller.

TABle 2: Power flow results of voltage in IEEE 30-bus system including microgrid and STATCOM controller.

\begin{tabular}{lccc}
\hline \multicolumn{4}{c}{ Voltage magnitude in per unit } \\
Buses & Base case & With MG & With MG \& FACTS \\
\hline Bus 1 & 1.06 & 1.06 & 1.06 \\
Bus 2 & 1.043 & 1.043 & 1.043 \\
Bus 3 & 1.0109026 & 1.006818 & 1.009946 \\
Bus 4 & 1.0000539 & 0.99518 & 0.998932 \\
Bus 5 & 1 & 1 & 1 \\
Bus 6 & 1.00040024 & 0.994788 & 0.99947 \\
Bus 7 & 0.99187422 & 0.988475 & 0.99947 \\
Bus 8 & 1.01 & 1.01 & 0.99104 \\
Bus 9 & 1.00516937 & 1.003427 & 1.01 \\
Bus 10 & 1 & 1 & 1.004794 \\
Bus 11 & 1 & 1 & 1 \\
Bus 12 & 1.00681984 & 1.003427 & 1 \\
Bus 13 & 1 & 0.987513 & 0.993152 \\
Bus 14 & 0.99124229 & 0.980787 & 0.988467 \\
Bus 15 & 0.98654462 & 0.994828 & 0.996998 \\
Bus 16 & 0.99637152 & 0.992823 & 0.993503 \\
Bus 17 & 0.99332895 & 0.974721 & 0.979772 \\
Bus 18 & 0.9785084 & 0.974457 & 0.977923 \\
Bus 19 & 0.97705653 & 0.980006 & 0.982618 \\
Bus 20 & 0.98196494 & 0.988266 & 0.992154 \\
Bus 21 & 0.99071004 & 0.985527 & 0.991603 \\
Bus 22 & 0.98954412 & 0.960667 & 0.978467 \\
Bus 23 & 0.97395893 & 0.943003 & 0.974167 \\
Bus 24 & 0.96601939 & 0.873522 & 0.965257 \\
Bus 25 & 0.94069283 & 0.852789 & 0.946585 \\
Bus 26 & 0.92151129 & 0.841286 & 0.969968 \\
Bus 27 & 0.93422492 & 0.981543 & 0.997718 \\
Bus 28 & 0.9982865 & 0.721993 & 0.934573 \\
Bus 29 & 0.88459486 & 0.64992 & 0.954784 \\
Bus 30 & 0.88341569 & 0.65994 & 1.009995 \\
Bus 31 & $\ldots$ & 0.668909 & 1.009995 \\
Bus 32 & $\ldots$ & 0.668508 & 1.009954 \\
Bus 33 & $\ldots$ & 0.668918 & 1.01 \\
\hline & & &
\end{tabular}

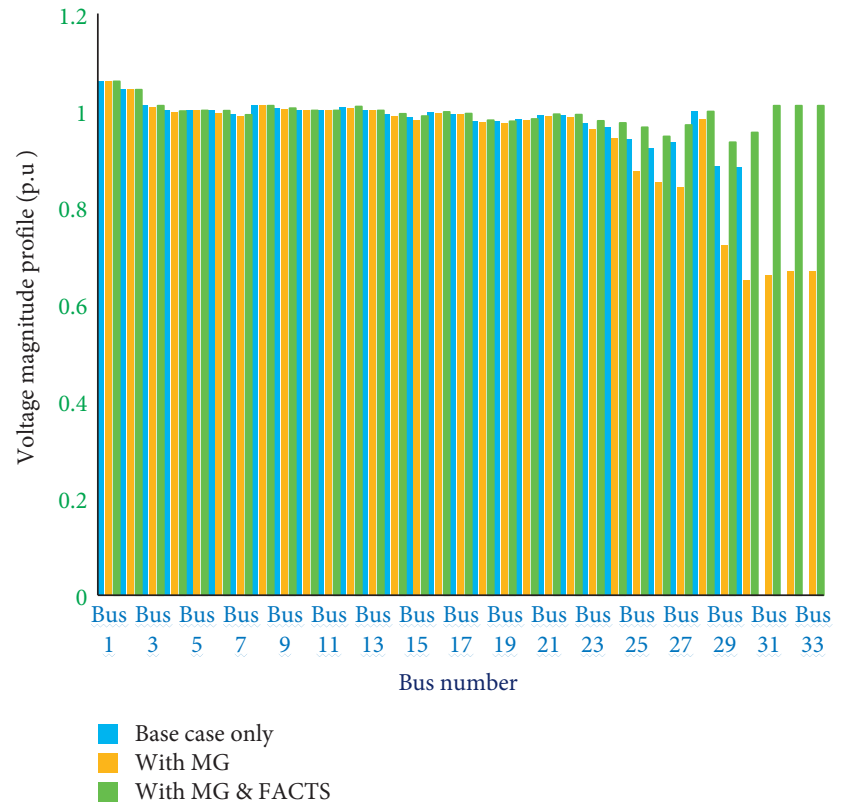

Figure 11: Base case, with microgrid, and STATCOM controller.

2.4.4. Summarized Flow Chart. The IEEE 30-bus system and microgrid were modelled using MATLAB/PSAT software for integration system. The weakest buses identification methods are continuous power flow (CPF), voltage stability indices (VSI), line stability index (LSI), fast voltage stability index (FVSI), new voltage stability index (NVSI), line voltage stability index (LVSI), and voltage collapse proximity indicator (VCPI). From those techniques, we proposed continuation power flow (CPF) method for identifying the collapsed bus of the IEEE 30-bus system. So, the continuation power flow was applied to the IEEE 30-bus system using MATLAB/PSAT software and the voltage profiles of 
TABLE 3: Total generation, power consumption, and total power losses in the IEEE 30-bus test system with and without microgrid and FACTS.

\begin{tabular}{lccc}
\hline & \multicolumn{2}{c}{ Voltage magnitude in per unit } \\
IEEE 30-bus system & Base case (p.u.) & With MG (p.u.) & With MG \& FACTS (p.u.) \\
\hline Total generation real power (p.u.) & 12.8056 & 13.236 & 13.23677 \\
Total generation reactive power (p.u.) & 2.87686 & 3.292914 & 3.197345 \\
Total load real power (p.u.) & 12.51 & 12.99579 & 13.0362281 \\
Total load reactive power (p.u.) & 2.73345 & 2.779339 & 2.7999962 \\
Total loss real power (p.u.) & 0.29560 & 0.397967 & 0.359338 \\
Total loss reactive power (p.u.) & 0.14340 & 0.245767 & 0.129539 \\
\hline
\end{tabular}

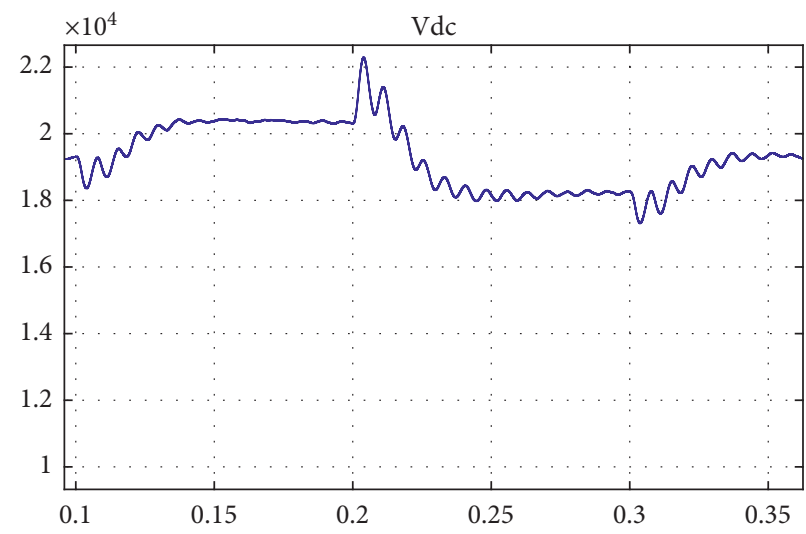

(a)

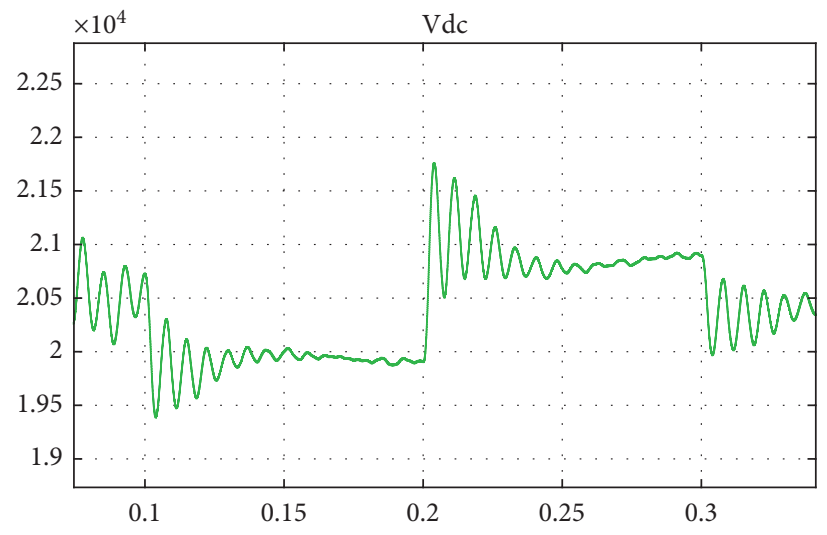

(b)

Figure 12: The DC voltage with (a) PI control and (b) fuzzy-PI control.

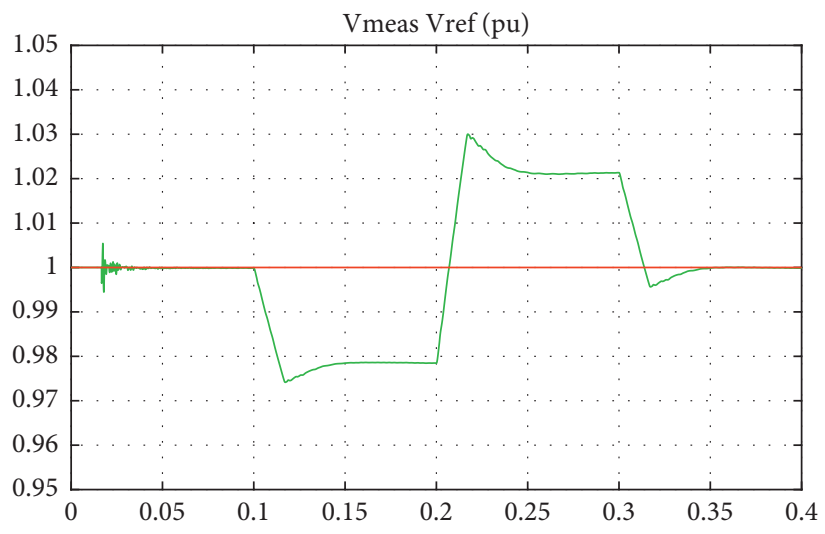

(a)

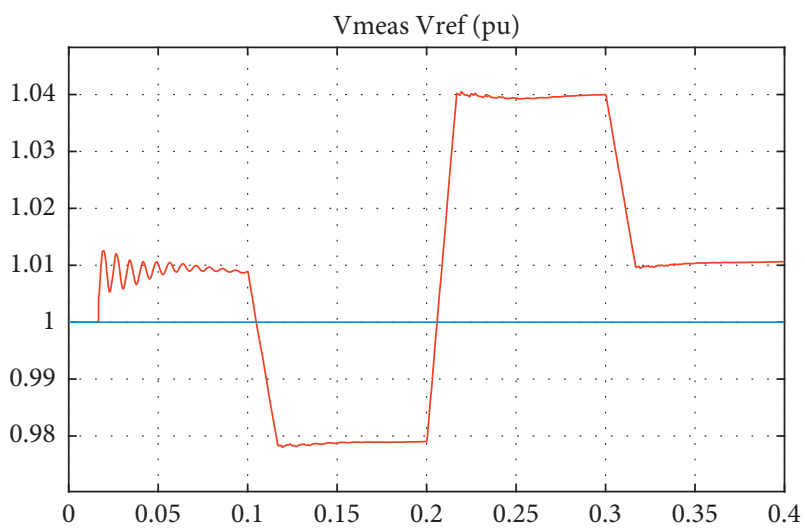

(b)

FIgURE 13: Voltage measurement: (a) with PI and (b) with fuzzy and PI controllers.

the buses were evaluated. From the results, we observed that bus 30 has the lowest voltage magnitude of 0.88341569 p.u. as shown in Table 1. So it was considered as the weakest bus of the IEEE 30-bus system. Then, the modelled microgrid was integrated into the weakest bus, that is, bus 30 , and continuation power flow (CPF) was again applied to determine the STATCOM controller placing and the weakest bus was found to also be bus 30 . Eventually, the continuation power flow results were evaluated for the introduction of microgrid and FACTS controllers into the network. Figure 7 shows the flow chart of the algorithm.

\section{Simulation Results and Discussions}

3.1. Simulation of Base Case. The simulation was conducted on the IEEE 30-bus system and the performance was assessed by applying power flow on the system. Figure 8 illustrates the single line diagram of the IEEE 30-bus system model using PSAT Simulink. The load flow simulation is performed after the PSAT model is loaded directly to its main N-R power flow. N-R iterative approach approximates the set of nonlinear equations simultaneously to a set of linear equations using Taylor expansion. By doing so, bus 


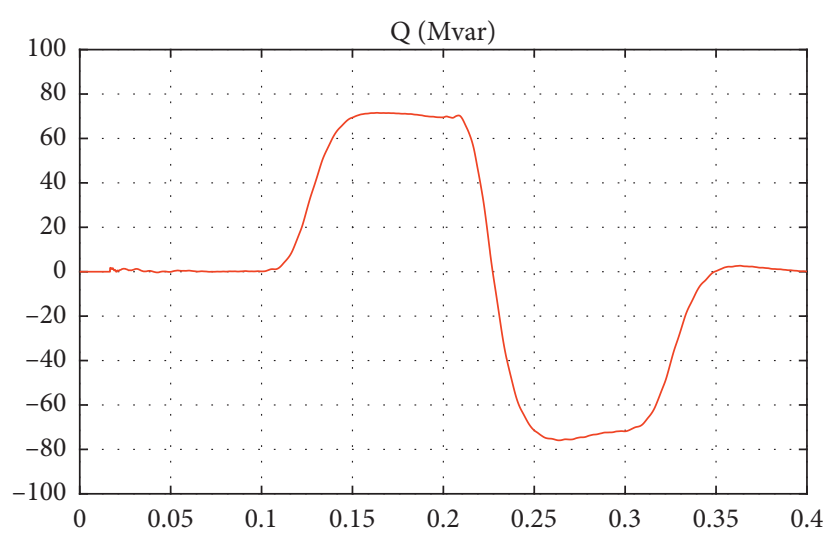

(a)

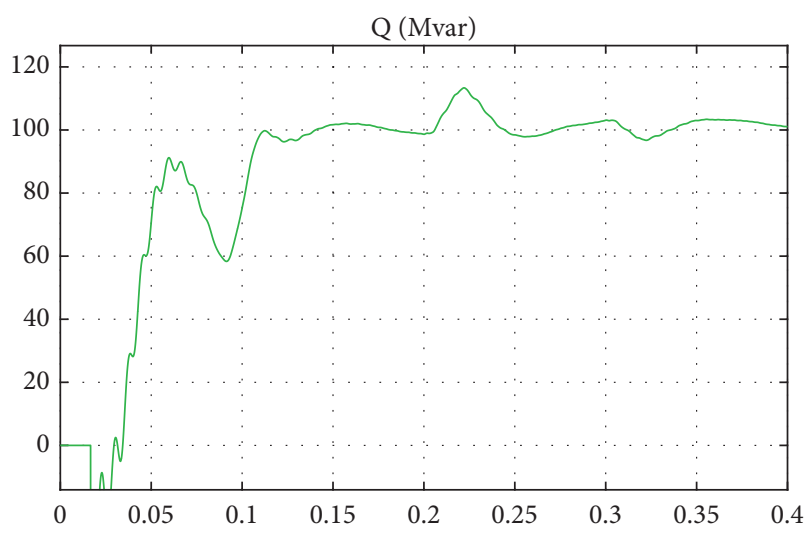

(b)

Figure 14: Reactive power: (a) with PI controller and (b) with fuzzy-PI controller.

TABLE 4: Value of the wind component in the microgrid system.

\begin{tabular}{lcc}
\hline No. & Component & Values \\
\hline 1 & Power rating & $5 \mathrm{MVA}$ \\
2 & Voltage rating & $69 \mathrm{kv}$ \\
3 & Rated frequency & $60 \mathrm{~Hz}$ \\
4 & Stator resistance (Rs) & $0.01 \mathrm{p} . \mathrm{u}$. \\
5 & Stator reactance (Xs) & $0.1 \mathrm{p} . \mathrm{u}$. \\
6 & Rotor resistance (Rr) & $0.01 \mathrm{p} . \mathrm{u}$. \\
7 & Rotor reactance (Xr) & $0.08 \mathrm{p} . \mathrm{u}$. \\
8 & Magnetization reactance $(\mathrm{Xm})$ & $3.00 \mathrm{p} . \mathrm{u}$. \\
9 & Pitch control gain (Kp) & $10 \mathrm{p} . \mathrm{u}$. \\
10 & Time constant (Tp) & $3 \mathrm{sec}$ \\
11 & Voltage control gain (Kv) & $10 \mathrm{p} . \mathrm{u}$. \\
\hline
\end{tabular}

voltage, voltage angle, and active and reactive power flow are computed using an iterative approach of the N-R simulation process. After running the power flow, the voltage magnitude, the power, and line flow were obtained and checked. Accordingly, the lowest voltage is 0.883416 p.u., which is that of bus 30 . Then, it is chosen as the location for microgrid integration.

\subsection{Simulation of IEEE 30-Bus System with Microgrid.} The microgrid, which is connected to the IEEE 30-bus system, consists of a $6 \mathrm{MW}$ wind and 7.5 MW PV energy resources as optimally modelled in [33]. The photovoltaic system has to supply its own load from its bus and the wind energy source has to supply its own load from its bus as well. When they were brought to a single bus together with their buses and loads, they formed a microgrid system having three buses as shown in Figure 9. After that, the microgrid was integrated into the weakest bus of IEEE 30-bus system as indicated above. Therefore, the overall microgrid integrated IEEE 30-bus standard system would have 33 buses, 24 loads, 39 lines, 7 generators, and 6 transformers. Because of the randomness nature of the solar and wind power resources in the microgrid system, the generated power increased or decreased depending on the level of solar irradiation and wind speed.
TABLE 5: Parameters of the PV component of microgrid.

\begin{tabular}{lcc}
\hline No. & Component & Values \\
\hline 1 & Power rating & $7.5 \mathrm{MVA}$ \\
2 & Voltage reference & $1.045 \mathrm{p.u}$. \\
3 & Inverter response time (Tp, Tq) & $0.015,0.015$ \\
4 & Voltage PI controller gains (Kv, Ki) & $0.0868,50.9005$ \\
\hline
\end{tabular}

The integration of the microgrid system into the network is, therefore, an exceptionally challenging task with power quality issues such as voltage fluctuations, power factor reduction, and high-power losses. Hence, adding STATCOM controller to the system is a significant solution to solve such problems.

The lowest voltage is found in bus 30 of the IEEE 30-bus system including the microgrid buses as described above. Thus, bus 30 with a magnitude of 0.64993 p.u. is the weakest and most collapsed bus, which can be an appropriate location of STATCOM.

Because of its advantages mentioned in [27], STATCOM controller is selectively installed in parallel to bus 30 to improve the voltage profile of the system by compensating reactive power.

Moreover, the fluctuation of voltage and reduction of power angle due to the integration of microgrid cause power loss, which lowers the performance of the power system.

3.3. Simulation Results of IEEE 30-Bus System including Microgrid and STATCOM. Figure 10 below shows the single line diagram of the IEEE 30-bus system with microgrid and STATCOM integrated at bus 30 in parallel. The results showed that the voltage profile is increased compared to both the base case and that with only microgrid-integrated systems.

For instance, voltage magnitudes for buses 29, 30, 31, 32, and 33 are increased from per-unit values of 0.721993 , $0.64992,0.65994,0.668909$, and 0.668918 to per-unit values of $0.934573,0.954784,1.009995,1.009995$, and 1.01, 
TABLE 6: Value of STATCOM components.

\begin{tabular}{lcr}
\hline No. & Component & Values \\
\hline 1 & Power & $100 \mathrm{MVA}$ \\
2 & Voltage & $230 \mathrm{kv}$ \\
3 & Frequency & $60 \mathrm{~Hz}$ \\
4 & Gain and time constant of the current control (Kr, Tp) & 50 p.u., 0.1 sec \\
5 & Max and min current & 1.2 p.u., 0.8 p.u. \\
\hline
\end{tabular}

TABLE 7: Parameter values of STATCOM controller.

\begin{tabular}{lcc}
\hline No. & Component & Values \\
\hline 1 & Reference voltage & 1 p.u. \\
2 & Droop (p.u./100 MVA) & 0.03 \\
3 & Voltage regulator gains (kp, ki) & 12,300 \\
4 & Iq regulator gains (kp, ki) & 5,4 \\
5 & DC-link voltage gain & 6.5 \\
6 & Active power gain & 200 \\
7 & Reactive power gain & 800 \\
\hline
\end{tabular}

respectively (see Table 2). These values elaborate specifically that STATCOM has a capability to improve the power flow capacity and voltage profile in the microgrid-integrated IEEE 30-bus system.

The details of wind power, photovoltaic power, and STATCOM controller parameters and values are given in Appendix A, Table 4, Appendix B, Table 5, and Appendix C, Tables 6 and 7, respectively.

\section{Summarized Results}

(a) The per-unit value of voltage magnitude is increased after incorporating STATCOM controller in the interconnected microgrid system. However, without the STATCOM controller, the per-unit voltage magnitude is fluctuating/decreased in a microgridintegrated network system. This is because of the randomness nature of wind and solar irradiation. The per-unit voltage comparison of the base case with microgrid and base case with both microgrid and STATCOM is represented clearly in Figure 11 below. Table 1 shows the per-unit magnitude of voltage profile for all the concerned test systems.

On the Other hand, the real power loss for the base case is 0.127933 p.u. and it increased to 0.230291 p.u (see Table 3) using microgrid integration into the base case. This is due to the intermittent nature of renewable energy sources resulting in voltage fluctuation, which can increase power loss.

By introducing STATCOM controller, the real power loss is decreased from 0.397967 p.u. to 0.35933 p.u (see Table 2). Therefore, we can summarize that the incorporation of microgrid systems with STATCOM controllers is very essential to minimize power losses and improve the system's power capacity and performance.

(b) The wave forms of DC link capacitor voltage, the perunit voltage measurement, and reactive power using proportional-integral (PI) control and fuzzy-PI controller for STATCOM are shown in Figures 12-14, respectively.

From Figure 12, the PI controller output is compared with the output of fuzzy-PI controller in Figures 12(a) and 12(b), respectively. The DC link voltage is fluctuating extremely until 0.35 seconds in PI controller. This variation is reduced to $0.25 \mathrm{sec}-$ onds by presenting fuzzy-PI controller. So, fuzzy-PI based controller of STATCOM is effective in reducing fluctuation, settling time, and damping the oscillations quickly. We can again notice that fuzzyPI controller gives smaller overshoot in response and settling time.

From Figure 13, the per-unit voltage magnitude is 1.03 for PI controller, whereas it is 1.04 for fuzzy-PI controller. It is also observed that the PI controller is taking more time to retort to the original stability position, whereas fuzzy-PI controller stabilizes instantly and there are no more transient oscillations.

The peak overshoot values for reactive power are 65 Mvar and 110 Mvar for PI and fuzzy-PI controllers, respectively (see Figure 14). Due to the high values of gain in PI, it causes peak overshoot waveforms at initial condition in fuzzy-PI controllers; however, the system is settled at 0.1 seconds, whereas it is settled at 0.35 seconds for PI controller alone.

Hence, from the above figures, we can conclude that the performance of fuzzy logic with proportional-integral (fuzzy-PI) controller for STATCOM device gives low peak overshoot and quick settling time. In addition, the proposed controller is effective in settling the final value and in damping the oscillations quickly. Thus, fuzzy-PI controller is proved to give improved performance compared to PI controller in STATCOM applications.

\section{Conclusion}

The modelling of a $6 \mathrm{MW}$ DFIG wind and $7.5 \mathrm{MW}$ photovoltaic based microgrid generation system was integrated and configured into the weak bus 30 in the IEEE 30-bus test system using MATLAB/PSAT environment. The power flow using N.R method was performed for the base case and with microgrid-integrated system with STATCOM controller. The microgrid-integrated system reduced the high voltage fluctuation and high-power losses. The parallel connection of the controller in the integrated system improved reactive power compensation and enhance the voltage profiles of the buses as well as minimizing line 
losses. Additionally, fuzzy-PI controller gives a good result compared to PI controller alone. Generally, this work demonstrates that the integration of microgrid with fuzzyPI based STATCOM controller has played a significant role in increasing the system capacity while minimizing voltage fluctuation and line losses.

\section{Appendix}

\section{A. The Parameters of the Wind Components of the Microgrid System in the Distribution Network}

The parameters of the wind components of the microgrid system in the distribution network are provided in Table 4.

\section{B. The Parameters of the PV Components of the Microgrid System in the Distribution Network}

The parameters of the PV components of the microgrid system in the distribution network are provided in Table 5.

\section{Different Parameters in STATCOM Controller}

Different parameters in STATCOM controller are provided in Tables 6 and 7.

\section{Data Availability}

The data used to support the findings of this work are accessible from the corresponding author upon request.

\section{Conflicts of Interest}

The authors declare that there are no conflicts of interest regarding the publication of this paper.

\section{References}

[1] M. J. Burke and J. C. Stephens, "Political power and renewable energy futures: a critical review," Energy Research \& Social Science, vol. 35, pp. 78-93, 2018.

[2] N. Enteria, H. Awbi, and H. Yoshino, "Application of renewable energy sources and new building technologies for the Philippine single family detached house," International Journal of Energy and Environmental Engineering, vol. 6, no. 3, pp. 267-294, 2015.

[3] T. Porsinger, P. Janik, Z. Leonowicz, and R. Gono, "Modelling and optimization in microgrids," Energies, vol. 10, no. 4, pp. 523-622, 2017.

[4] A. Mohanty, M. Viswavandya, D. K. Mishra, P. K. Ray, and S. Pragyan, "Modelling \& simulation of a PV based micro grid for enhanced stability," Energy Procedia, vol. 109, pp. 94-101, 2017.

[5] H. Bakir and A. A. Kulaksiz, "Modelling and voltage control of the solar-wind hybrid micro-grid with optimized STATCOM using GA and BFA," Engineering Science and Technology, an International Journal, vol. 23, no. 3, pp. 576-584, 2019.

[6] S. A. Taher and S. A. Afsari, "Optimal location and sizing of DSTATCOM in distribution systems by immune algorithm,"
International Journal of Electrical Power \& Energy Systems, vol. 60, pp. 34-44, 2014.

[7] A. Agbedahunsi, M. Sumner, E. Christopher, A. Watson, A. Costabeber, and R. Parashar, "Frequency control improvement within a microgrid, using enhanced STATCOM with energy storage," in Proceedings of the 6th IET International Conference on Power Electronics, Machines and Drives (PEMD 2012), no. 592, pp. 1-6, Bristol, UK, 2012.

[8] S. K. Singh, L. Phunchok, and Y. R. Sood, "Voltage profile and power flow enhancement with FACTS controllers," International Journal of Engineering Research \& Technology, vol. 1, no. 5, pp. 1-5, 2012.

[9] C. Davidson, "Power electronic topologies for FACTS," CIGRE Green Books, vol. 20, pp. 1-26, 2019.

[10] Q. Wang, B. Wang, W. Xu, and J. Xu, "Research on STAT$\mathrm{COM}$ for reactive power flow control and voltage stability in microgrid," 13th IEEE Conference on Industrial Electronics and Applications (ICIEA), vol. 12, no. 61671338, pp. 24742479, 2018.

[11] F. Iqbal, M. T. Khan, and A. S. Siddiqui, "Optimal placement of DG and DSTATCOM for loss reduction and voltage profile improvement," Alexandria Engineering Journal, vol. 57, no. 2, pp. 755-765, 2018.

[12] A. Vinayagam, A. Aziz, K. S. V. Swarna, S. Khoo, and A. Stojcevski, "Power quality impacts in a typical microgrid," in Proccedings of the International Conference on Sustainable Energy and Environmental Engineering (SEEE 2015) Power, pp. 77-82, Bangkok, Thailand, 2015.

[13] B. Rani and A. Reddy, "Optimal allocation and sizing of multiple DG in radial distribution system using binary particle swarm optimization," International Journal of Intelligent Engineering and Systems, vol. 12, no. 1, pp. 290-299, 2019.

[14] C. T. D. Pipalava, "Voltage profile improvement in power system using series and shunt type FACTS controller," International Journal of Science and Research, vol. 4, no. 2, pp. 2453-2456, 2015.

[15] H. Bakir and A. A. Kulaksiz, "Modelling and voltage control of the solar-wind hybrid micro-grid with optimized STATCOM using GA and BFA," Engineering Science and Technology, an International Journal, vol. 25, pp. 1-6, 2019.

[16] M. Mohaddes, A. M. Gole, and P. G. McLaren, "A neural network controlled optimal pulse-width modulated STATCOM," IEEE Transactions on Power Delivery, vol. 14, no. 2, pp. 481-488, 2018.

[17] M. Balavar, "Using neural network to control STATCOM for improving transient stability," Journal of Artificial Intelligence in Electrical Engineering, vol. 1, no. 1, pp. 26-31, 2012.

[18] S. Mohagheghi, J. W. Park, R. G. Harley, G. K. Venayagamoorthy, and M. L. Crow, "An adaptive neural network identifier for effective control of a static compensator connected to a power system," in Proceedings of the International Joint Conference on Neural Networks, vol. 4, pp. 2964-2969, Portland, Columbia, 2015.

[19] G. Abad, J. Lopez, M. A. Rodriguez, L. Marroyo, and G. Lwanski, Doubly Fed Induction Machine, John Wiley \& Sons, Hoboken, NJ, USA, 1st edition, 2011.

[20] N. Bhole and S. S. C. Bhambhori, "Enhancement of power quality in grid connected photovoltaic system using predictive current control technique," vol. 5, no. 7, pp. 549-553, 2017.

[21] C. Paper, "Microgrid simulation for voltage sag/swell mitigation using dynamic voltage restorer application of dynamic voltage restorer in microgrid for voltage sag/swell mitigation," in Proceedings of the 2015 IEEE Power, Communication and 
Information Technology Conference (PCITC), pp. 978-4799, Bhubaneswar, India, 2015.

[22] A. Durgadevi, S. Arulselvi, and S. P. Natarajan, "Photovoltaic modeling and its characteristics," in Proceedings of the International Conference on Emerging Trends in Electrical and Computer Technology, ICETECT 2011, pp. 469-475, Nagercoil, India, 2011.

[23] X. Lyu, Z. Xu, and J. Zhao, “A coordinated frequency control strategy for photovoltaic system in microgrid," Journal of International Council on Electrical Engineering, vol. 8, no. 1, pp. 37-43, 2018.

[24] F. H. Gandoman, "Review of FACTS technologies and applications for power quality in smart grids with renewable energy systems," Renewable and Sustainable Energy Reviews, vol. 82, pp. 502-514, 2018.

[25] L. O. Aghenta and M. T. Iqbal, "Design and dynamic modelling of a hybrid power system for a house in Nigeria," International Journal of Photoenergy, vol. 2019, Article ID 6501785, 13 pages, 2019.

[26] A. K. Sahoo, S. S. Dash, and T. Thyagaraja, "Power flow study including FACTS devices," Journal of Applied Sciences, vol. 10, no. 15, pp. 1563-1571, 2010.

[27] S. Devi and M. Geethanjali, "Optimal location and sizing determination of distributed generation and DSTATCOM using particle swarm optimization algorithm," International Journal of Electrical Power \& Energy Systems, vol. 62, pp. 562-570, 2014.

[28] M. Hedayati and H. Abbasi, "Optimal voltage and frequency control of a microgrid system using a teaching-learning based optimization (TLBO) algorithm," vol. 3, no. 8, pp. 35-43, 2015.

[29] H. Ameli, M. T. Ameli, and S. H. Hosseinian, "Multi-stage frequency control of a microgrid in the presence of renewable energy units," Electric Power Components and Systems, vol. 45, no. 2, pp. 159-170, 2017.

[30] V. Swathi and E. Engineering, "Fuzzy logic control of STATCOM for voltage regulation,” vol. 5, no. 7, pp. 24562466, 2016.

[31] A. Abdo-Allah, T. Iqbal, and K. Pope, "Modeling, analysis, and state feedback control design of a multizone HVAC system," Journal of Energy, vol. 2018, Article ID 4540387, 11 pages, 2018.

[32] I. Ullah, W. Gawlik, and P. Palensky, "Analysis of power network for line reactance variation to improve total transmission capacity," Energies, vol. 9, no. 11, pp. 936-1020, 2016.

[33] M. G. Yenalem and P. Hinga, "Modelling and optimal sizing of grid-connected micro grid system using HOMER in Bahir Dar city, Ethiopia 2 literature review," International Journal of Power Systems, vol. 5, pp. 1-12, 2020. 